\title{
Usefulness of resveratrol supplementation in decreasing cardiometabolic risk factors comparing subjects with metabolic syndrome and healthy subjects with or without obesity: meta-analysis using multinational, randomised, controlled trials
}

\author{
Consolato Sergi ${ }^{1-4}$, Bonnie Chiu ${ }^{3}$, Joseph Feulefack ${ }^{3}$, Fan Shen ${ }^{3}$, Brian Chiu ${ }^{3}$
}

\author{
${ }^{1}$ Institute of Biomedical and Pharmaceutical Sciences, Key Laboratory \\ of Fermentation Engineering (Ministry of Education), Hubei Provincial Cooperative \\ Innovation, Center of Industrial Fermentation, Hubei Key Laboratory of Industrial \\ Microbiology, Hubei University of Technology, Wuhan, China \\ 2Tianyou Hospital, Wuhan University of Science and Technology, Wuhan, Hubei, China \\ ${ }^{3}$ Department of Laboratory Medicine and Pathology, Faculty of Medicine and \\ Dentistry, University of Alberta. Edmonton, Alberta, Canada \\ ${ }^{4}$ Department of Pediatrics, Stollery Children's Hospital, Edmonton, Alberta, Canada
}

Submitted: 22 December 2019

Accepted: 18 April 2020

Arch Med Sci Atheroscler Dis 2020; 5: e98-e111 DOI: https://doi.org/10.5114/amsad.2020.95884

Copyright (c) 2020 Termedia \& Banach

\begin{abstract}
Introduction: Resveratrol (RES), a natural polyphenolic compound, has been linked to some beneficial effects against cardiovascular disease (CVD).

Material and methods: We conducted a systematic search to conduct a meta-analysis on cardiometabolic risk factors modulated by RES targeting patients with metabolic syndrome (Met-S) and Obese/Healthy $(\mathrm{O} / \mathrm{H})$ subjects. The PICO (Patient, Intervention, Comparison, Outcome) research question was: Does RES among patients with Met-S and $\mathrm{O} / \mathrm{H}$ subjects reduce the cardiometabolic risk? The first group was affected with MetS, which is defined as a clustering of abdominal obesity, dyslipidaemia, hyperglycaemia, and hypertension in a single individual. The second group was composed of 'obese/healthy' individuals, i.e. healthy subjects with or without obesity. We performed a literature search of MEDLINE/ PubMed, Scopus, and Google Scholar for randomised, controlled trials (RCT) that estimated the effects of RES on cardiometabolic risk factors.

Results: We found 780 articles, of which 63 original articles and reviews were identified. Data from 17 well-conducted RCT studies, comprising 651 subjects, were extracted for analysis. Overall, RES had a significant influence on Homeostatic Model Assessment-Insulin Resistance (HOMA-IR), resulting in a mean difference of $-0.520665(95 \% \mathrm{Cl}:-1.12791 ;-0.01439$; $p=0.00113)$. In Met-S, RES significantly reduced glucose, low-density lipoprotein-cholesterol (LDL-C), and total cholesterol (T-Chol) as detected by the mean difference of $-1.069(95 \% \mathrm{Cl}:-2.107,-0.032 ; p=0.043),-0.924$ (95\% Cl: $-1.804,-0.043 ; p=0.040)$, and $-1.246(95 \% \mathrm{Cl}:-2.314,-0.178$; $p=0.022$ ), respectively.

Conclusions: Despite some heterogeneity in the populations, RES supplementation seems to improve cardiometabolic health, decreasing some risk factors (HOMA-IR, LDL-C, and T-Chol) associated with CVD.
\end{abstract}

Corresponding author: Prof. Consolato Sergi Department of Lab Medicine and Pathology University of Alberta

Canada

Phone: +1 7804077951

E-mail: sergi@ualberta.ca

Key words: heart, metabolic syndrome, resveratrol, meta-analysis, randomised, controlled trial. 


\section{Introduction}

There is a growing interest in using natural compounds as potential therapeutics for chronic diseases or cancer preventive agents [1]. Polyphenols belong to a category of chemical compounds that are classified into several classes according to their chemical type, such as phenolic acids, flavonoids, stilbenes, and lignans. The beneficial effects of flavonoids in atherosclerosis progression and cardiovascular disease has been reported recently because dietary flavonoids reduce oxidative stress, exert anti-inflammatory actions, are anti-thrombogenic, strengthen endothelial function, modify lipid levels, and adjust glucose metabolism.

Cardiovascular disease (CVD) is the leading cause of morbidity and mortality worldwide, with an increasing environmental burden hitting especially middle-income countries [2-5]. Atherosclerosis, the leading cause of ischaemic heart disease (IHD), cerebrovascular, and peripheral vascular diseases, is a progressive and complicated disease process often associated with recognised risk factors such as hypertension, hypercholesterolaemia, type 2 diabetes mellitus (T2DM), and tobacco smoking $[3,6,7]$. The association of glucose intolerance with insulin resistance, hypertension, dyslipidaemia, and central obesity predisposing individuals to the development of T2DM and CVD has been described as 'metabolic syndrome' (Met-S) [8-21]. More than a third of American adults with body mass index (BMI) higher of $30 \mathrm{~kg} / \mathrm{m}^{2}$ may have a higher risk of developing conditions like T2DM, CVD, and stroke than the general population. However, a proportion of obese adults defy the odds, maintaining metabolic health despite the excess weight, and they have been labelled Obese/Healthy $(\mathrm{O} / \mathrm{H})[22,23]$.

Resveratrol (3,4',5-trihydroxy-trans-stilbene, $\left.\mathrm{C}_{14} \mathrm{H}_{12} \mathrm{O}_{3}, \mathrm{RES}\right)$, a natural polyphenolic compound that exists in a large variety of plant species, including grapes, peanuts, and berries, has long been used as a herbal remedy and dietary supplement. The concept of the "French paradox" may suggest that the French nutritional style is quite healthy [24]. French people have a relatively low incidence of CVD despite having a diet rich in saturated fats, and red wine consumption may be responsible for lowering of the serum lipids [25]. Since 1992, there has been a rise of studies investigating the health benefits of RES in cardiovascular health [26-28]. RES is known for its antioxidant and anti-inflammatory properties and for its ability to upregulate endothelial NO synthase (eNOS). Its ability to scavenge ${ }^{\circ} \mathrm{OH} / \mathrm{O}_{2}{ }^{\cdot-}$ and peroxyl radicals may be crucial in limiting the lipid peroxidation processes in CVD $[29,30]$. Several preclinical studies on animal models have indeed highlight- ed beneficial effects of RES on CVD. These studies are underpinned by the identification of numerous molecular targets, including silent information regulator 2/sirtuin 1 (SIRT-1), AMP-activated protein kinase (AMPK), nuclear factor-like 2 (Nrf2), and nuclear factor- $\kappa \mathrm{B}$ (NF- $\mathrm{KB})$, among others [3137]. RES is also beginning to be the target of social and ideological debates in some cultures [38-44]. On the other hand, some systematic reviews of randomised, controlled trials (RCTs) seem to have failed to indicate specific beneficial effects of RES supplementation for selected risk factors for CVD $[45,46]$. The prevalence of MetS is rapidly increasing worldwide. In fact, MetS is not only increasing in industrialised countries but also in developing countries associated with a lifestyle change, including some Asian and African countries. MetS is impacting the global incidence of life-threatening CVD such as stroke and myocardial infarction. Effective treatment for cardiovascular risk factors in MetS often requires pharmacological intervention. To the best of our knowledge, the available pharmacological tools are usually not sufficiently effective, and additional protocols may be needed to prevent the development of major cardiovascular complications in MetS.

Considering recent RCTs $[47,48]$, and T2DM systematic reviews [49], we hypothesised that RES could reduce the cardiometabolic risk factors for CVD. In this paper, we report our results from an investigation using a comprehensive meta-analysis of published RCTs to quantitatively assess the effects of RES on reducing CVD risk factors comparing subjects with Met-S and subjects labelled $\mathrm{O} / \mathrm{H}$.

\section{Material and methods}

\section{Search strategy}

We performed a literature search in MEDLINE/ PubMed (up to October 31, 2016; http://www. ncbi.nlm.nih.gov/pubmed/), Scopus, and Google Scholar (up to October 31, 2016) using the following search terms in the title and abstract: 'Resveratrol' or 'Resveratrols' (plural). We searched the key terms alongside the following limitations: English-language, human studies, and clinical trials. To qualify for inclusion ("inclusion criteria") the studies had to be randomised, controlled trials comparing interventions that differed only in resveratrol condition. If other interventions were given, they had to be the same in all treatment groups. Only articles that were published in English-language, peer-reviewed journals were included. Reference lists and reviews were further handsearched to identify RCTs examining the effects of RES on two groups of subjects. The first group was affected with MetS with or without coronary artery disease (CAD). Met-S is defined as a clustering of 
key cardiovascular risk factors; namely, abdominal obesity, dyslipidaemia, hyperglycaemia, and hypertension in a single individual. Interestingly, some names, such as syndrome $X$, dysmetabolic syndrome, insulin resistance syndrome, and the "deadly quartet" have also been used. CVD may have a broad definition, but usually subjects with CVD present with CAD, MetS, and/or hypertension. The second group that we considered in our meta-analysis is labelled 'obese/healthy' $(\mathrm{O} / \mathrm{H})$, i.e. healthy with or without obesity. The justification is that during the past 15 years numerous studies have shown an 'obesity paradox'. In fact, despite the adverse effects that obesity may have on the risk factors associated with CVD and other chronic diseases, patients with overweight or obesity, who show a 'healthy habit', often astoundingly harbour a better prognosis than leaner patients. Our investigative research group aims to perform accurately systematic reviews adhering strictly to the Preferred Reporting Items for Systematic Reviews and Meta-Analyses (PRISMA) guidelines and relative statements at the University of Alberta, Edmonton, Canada [1, 10, 50-59]. The PICOS criteria (Patient/Problem, Intervention, Comparison groups, Outcome, and Setting) were used for both research question and title.

\section{Data extraction}

All published papers were reviewed by four of the authors (BoC, JF, BrC, and CS). An initial qualitative assessment was performed double-blind, and notes were discussed to identify flaws and determine a quality coefficient for each paper. In the initial data extraction phase, baseline characteristics from each of the selected papers were extracted and tabulated in a spreadsheet. These components included: author, year, study design, and participant information. Pre- and post-treatment values of selected parameters and their respective standard deviations (SD) were extracted for the interventional and control groups of each study. Mean differences and SD differences were obtained directly from the retrieved scientific literature. If these values were not provided, they were calculated using the formulas mean difference = (post-treatment value - pre-treatment value) and $\mathrm{SD}_{\text {diff }}=\sqrt{\mathrm{SD}_{\text {pre-treatment }}}{ }^{2} / n+\mathrm{Sd}_{\text {post-treatment }} 2 / n[60]$. We found that these formulas gave values to compare the RCT uniformly. Not all papers used the same units. Consequently, unit conversions were carried out using conversion formulas (Table I).

HOMA-IR stands for Homeostatic Model Assessment of Insulin Resistance, which evaluates both the presence and extent of any insulin resistance that may be encountered in a patient. The healthy range is $1.0(0.5-1.4)$. If the HOMA-IR score is less than 1.0, there is a status of insulin-sensitivity that is optimal, while a value above 1.9 indicates early insulin resistance, and above 2.9 indicates significant insulin resistance. HOMA-IR is calculated by multiplying insulin rate (ulU/ml or $\mathrm{mU} / \mathrm{l}$ ) and the glycemia $(\mathrm{mg} / \mathrm{dl})$. The HOMA-IR calculation requires U.S. standard units and the use of specific conversions. With regard to insulin, we used $\mathrm{pmol} / / \mathrm{l}$ to $\mathrm{ulU} / \mathrm{ml}$ by dividing by $(\div) 6.945$, while for glucose we used $\mathrm{mmol} / \mathrm{l}$ to $\mathrm{mg} / \mathrm{dl}$ by multiplying by $(x) 18$.

We classified the studies into two groups: (1) Metabolic Syndrome (Met-S)/T2DM with and without $\mathrm{CAD}$ and (2) Obese/Healthy $(\mathrm{O} / \mathrm{H})$ (no metabolic syndrome/T2DM or CAD) [61]. In the final stage of data extraction, the most relevant data from the initial phase were narrowed down and tabulated for inputting into the Comprehensive Meta-Analysis (CMA) program (Biostat, Englewood, NJ, USA). Information about the studies included: study name and year, duration, classification, gender, the number of the subjects treated, and the number of those who were referred as controls. Information about the factors included: units, intervention mean difference, and intervention difference $\mathrm{SD}$, control mean difference, control difference SD,

Table I. Conversion formulas

\begin{tabular}{|lccc|}
\hline Factor & \multicolumn{2}{c|}{ Conversion } & Conversion formula \\
\cline { 2 - 4 } & From & To & $(\mathrm{mmol} / \mathrm{l}) \times 18$ \\
\hline Glucose & $\mathrm{mmol} / \mathrm{l}$ & $\mathrm{mg} / \mathrm{dl}$ & $(\mathrm{mU} / \mathrm{l}) / 6.945$ \\
\hline Serum Insulin & $\mathrm{mU} / \mathrm{l}$ & $\mu \mathrm{lU} / \mathrm{ml}$ & $(\mathrm{mmol} / \mathrm{l}) \times 38.6$ \\
\hline LDL-C & $\mathrm{mmol} / \mathrm{l}$ & $\mathrm{mg} / \mathrm{dl}$ & $(\mathrm{mmol} / \mathrm{l}) \times 38.6$ \\
\hline HDL-C & $\mathrm{mmol} / \mathrm{l}$ & $\mathrm{mg} / \mathrm{dl}$ & $(\mathrm{mmol} / \mathrm{l}) \times 38.6$ \\
\hline T-Chol & $\mathrm{mmol} / \mathrm{l}$ & $\mathrm{mg} / \mathrm{dl}$ & $(\mathrm{mmol} / \mathrm{l}) \times 88.5$ \\
\hline TG & $\mathrm{mmol} / \mathrm{l}$ & $\mathrm{mg} / \mathrm{dl}$ & $(\mathrm{g} / \mathrm{l}) \times 1000$ \\
\hline CRP & $\mathrm{g} / \mathrm{l}$ & $\mathrm{mg} / \mathrm{l}$ & \\
\hline
\end{tabular}

$L D L-C$ - low-density lipoprotein cholesterol, HDL-C - high-density lipoprotein cholesterol, T-Chol - total cholesterol, TG - triglycerides, $C R P-C$-reactive protein. 
and pre/post correlation. If data were available, we performed pre-/post-correlation calculations by finding the relationship between all treatment and control pre-treatment values and all treatment and control post-treatment values. We used the correlation function of Excel (CORREL) (Windows 10 Pro, Microsoft Corporation, Silicon Valley, CA, USA).

\section{Statistical analysis}

We performed the meta-analysis using the Comprehensive Meta-Analysis (CMA) software (Biostat, 14 North Dean Street, Englewood, NJ 07631 USA) [62]. A mixed-effects analysis was assigned to investigate the influence of RES on the cardiometabolic risk factors. Mixed effects models are useful when data are available that contain more than one source of random variability. In fact, an outcome may be measured more than once on the same person, i.e. repeated measures taken over time. In this scenario, we have to account for both within-person and across-person variability [63-66]. A comparison between interventional and control groups was made. To calculate the standardised mean difference between treatment and control groups, we used the mean difference of the control group minus the mean difference of the treatment group, divided by the SD of the change score. Moreover, we conducted an analysis across the Met-S and $\mathrm{O} / \mathrm{H}$ groups and a gender-specific analysis.

One of the significant aspects in our meta-analysis was to ensure that point estimates were not computed from a biased collection of studies. The benefit is that exaggeration of the actual effect size of treatment can be avoided. Hence, we assessed how many biases could be present in our meta-analysis and examined their potential impact on our findings. We used the Egger's method of bias assessment, which recommends the use of the inverse of the SE, i.e. precision, to predict the standardised effect size. All statistical analysis was carefully perused three times by three of the authors (BoC, JF, BrC) and verified by the senior author (CS).

\section{Results}

\section{Data sources and literature search}

A flow diagram outlining the process of study selection is shown in Figure 1. A total of 8821 articles were initially identified, and studies that did not involve humans were excluded, with 780 items remaining. Of these reports, there were 63 that were RCT and reviews involving RES. In the final stage of study selection following exclusion of duplicated, overlapping, and non-relevant studies, 17 articles of well-conducted RCTs were selected for inclusion [47, 67-84]. Exclusion criteria includ- ed studies that were duplicated, showed overlapping, or, according to the authors, were considered non-relevant. All studies were evaluated singly and scored by three authors (BoC, JF, BrC), and any inclusion or exclusion needed to have full consensus. These reports were then split into two groups (Met-S and $\mathrm{O} / \mathrm{H}$ ). In particular, Bhatt et al. (2012) [85] and Kumar et al. (2013) [73] had the same study, disguised as different studies with different authors. In examining the methods and results for those studies, it is apparent that they are the same study (same sample size with accurate same baseline values), just with two different durations. Thus, we decided to use Kumar's review because it was a more extended study. Fujitaka's 2011 study [86] has Dr. Das as a senior author, and Dr. Das was found guilty of research fraud. Some of his work has been retracted from the scientific literature. Thus, the results from that paper cannot be fully trusted, and all authors agreed and decided to exclude it. Unfortunately, Dr. Das, a prominent cardiovascular researcher with early research on catalase, glutathione, and superoxide dismutase, who had 19 papers retracted following findings of misconduct by the University of Connecticut (USA), died at the age of 67 on Sep 19, 2017. Dr. Das suffered a stroke because of the stress, although he defended himself and filed a lawsuit against the university.

\section{Study characteristics}

Table II summarises the characteristics of studies included in our meta-analysis. The 17 eligible studies comprised 651 subjects. Most of the studies (16 out of 17) used parallel design, with three studies using cross-over design. The total number

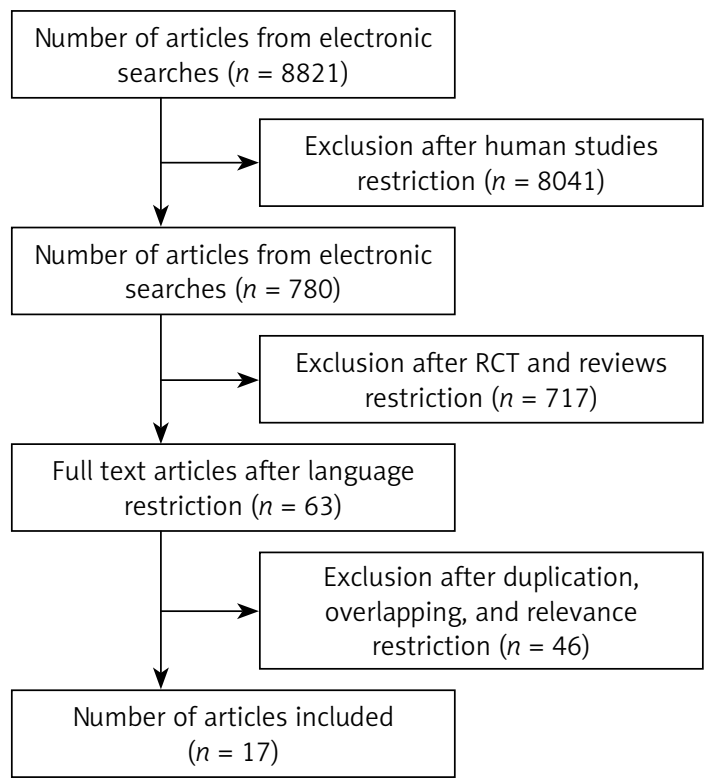

Figure 1. PRISMA-based flow-chart showing the selection process for articles of resveratrol included in the systematic review 
Table II. Eligible studies in alphabetical order $(n=17)$

\begin{tabular}{|c|c|c|c|c|c|c|c|c|}
\hline $\begin{array}{l}1^{\text {st }} \text { author [ref.]" } \\
\text { country }\end{array}$ & CSD & DUR & RES & $N$ & T-P and age & RES Group & Controls & BMI \\
\hline Agarwal [67] (2013), USA & $P$ & 30 & 400 & 41 & $\begin{array}{l}\text { Healthy } \\
\geq 18\end{array}$ & $N=20^{1}$ & $N=21(\mathrm{PBO})$ & - \\
\hline $\begin{array}{l}\text { Bashmakov [47] (2014), } \\
\text { Sweden }\end{array}$ & $\mathrm{P}$ & 60 & 100 & 24 & $\begin{array}{c}\text { T2DM } \\
54.0 \pm 10.1\end{array}$ & $N=14(\mathrm{c})$ & $N=10(\mathrm{PBO})$ & - \\
\hline $\begin{array}{l}\text { Brasnyo [68] (2011), } \\
\text { Hungary }\end{array}$ & $P$ & 30 & 10 & 19 & $\begin{array}{c}\text { T2DM } \\
57.9 \pm 7.9\end{array}$ & $N=10(\mathrm{c})$ & $N=9(\mathrm{PBO})$ & - \\
\hline $\begin{array}{l}\text { Chachay [69] (2014), } \\
\text { Australia }\end{array}$ & $P$ & 56 & 3000 & 20 & $\begin{array}{c}\text { Obese } \\
48.8 \pm 12.2\end{array}$ & $N=10(c)$ & $N=10(\mathrm{PBO})$ & 31.8 \\
\hline Dash [70] (2013), Canada & $\mathrm{C}-\mathrm{O}$ & 14 & $2000^{2}$ & 16 & $\begin{array}{l}\text { Obese } \\
45.8 \pm 8.8\end{array}$ & $N=8\left(\mathrm{p}^{2}\right)$ & $N=8(\mathrm{PBO})$ & $31.1 \pm 4.8$ \\
\hline $\begin{array}{l}\text { Faghihzadeh [71] (2015), } \\
\text { Iran }\end{array}$ & $\mathrm{P}$ & 84 & 500 & 50 & $\begin{array}{c}\text { NAFLD } \\
44.4 \pm 10.1\end{array}$ & $N=25(\mathrm{c})$ & $N=25(\mathrm{PBO})$ & $28.3 \pm 3.5$ \\
\hline Ghanim [72] (2010), USA & $\mathrm{P}$ & 42 & 40 & 20 & $\begin{array}{l}\text { Healthy } \\
36 \pm 5\end{array}$ & $N=10(\mathrm{c})$ & $N=10(\mathrm{PBO})$ & $21.8 \pm 0.5$ \\
\hline Kumar [73] (2013), India & $P$ & 182 & 250 & 57 & $\begin{array}{c}\text { T2DM } \\
57.7 \pm 8.9\end{array}$ & $\begin{array}{c}N=28 \\
(c+\text { OHAs })\end{array}$ & $\begin{array}{c}N=29 \\
\text { (OHAs only) }\end{array}$ & $24.7 \pm 3.6$ \\
\hline $\begin{array}{l}\text { Magyar [74] (2012), } \\
\text { Hungary }\end{array}$ & $\mathrm{P}$ & 90 & 10 & 40 & $\begin{array}{c}\text { CAD (stable), } \\
65.3 \pm 9.7\end{array}$ & $N=20(\mathrm{t})$ & $N=20(\mathrm{PBO})$ & $29.3 \pm 2.1$ \\
\hline $\begin{array}{l}\text { Mendez-del Villar [83] } \\
\text { (2014), Mexico }\end{array}$ & $P$ & 90 & 1500 & 24 & $\begin{array}{c}\text { Met-S } \\
\text { 30-50 years }\end{array}$ & $N=12(\mathrm{c})$ & $N=12(\mathrm{PBO})$ & - \\
\hline $\begin{array}{l}\text { Militaru [76] (2013), } \\
\text { Romania }\end{array}$ & $\mathrm{P}$ & 60 & 20 & 58 & $\begin{array}{c}\text { CAD (stable) } \\
64.9 \pm 5.8\end{array}$ & $N=29(c)$ & $N=29(\mathrm{Nil})$ & - \\
\hline $\begin{array}{l}\text { Movahed [77] (2013), } \\
\text { Iran }\end{array}$ & $\mathrm{P}$ & 45 & 1000 & 66 & $\begin{array}{c}\text { T2DM } \\
52.4 \pm 6.1\end{array}$ & $N=33(\mathrm{c})$ & $N=33(\mathrm{PBO})$ & $27.1 \pm 3.1$ \\
\hline $\begin{array}{l}\text { Poulsen [78] (2013), } \\
\text { Denmark }\end{array}$ & $P$ & 28 & 500 & 24 & $\begin{array}{l}\text { Obese } \\
44.7 \pm 12.1\end{array}$ & $N=12(\mathrm{t})$ & $N=12(\mathrm{PBO})$ & $32.5 \pm 2.1$ \\
\hline $\begin{array}{l}\text { Timmers [79] (2011), } \\
\text { Netherlands }\end{array}$ & $\mathrm{C}-\mathrm{O}$ & 30 & 150 & 22 & $\begin{array}{c}\text { Obese } \\
52.5 \pm 2.1\end{array}$ & $N=11(\mathrm{c})$ & $N=11(\mathrm{PBO})$ & $31.5 \pm 2.7$ \\
\hline $\begin{array}{l}\text { Tome-Carneiro [80] } \\
\text { (2013), Spain (Cardiovasc } \\
\text { Drugs Ther) }\end{array}$ & $P$ & 365 & 350 & 50 & $\begin{array}{l}\text { CAD stable } \\
60 \pm 12\end{array}$ & $N=25$ & $N=25$ & $29.7 \pm 5.1$ \\
\hline $\begin{array}{l}\text { Van der Made [81] } \\
\text { (2015), Netherlands }\end{array}$ & $\mathrm{C}-\mathrm{O}$ & 28 & 150 & 90 & $\begin{array}{l}\text { Obese } \\
60 \pm 7\end{array}$ & $N=45(\mathrm{c})$ & $N=45(\mathrm{PBO})$ & $28.3 \pm 3.2$ \\
\hline Yoshino [82] (2012), USA & $\mathrm{P}$ & 84 & 75 & 30 & $\begin{array}{l}\text { Healthy } \\
58.2 \pm 4.0\end{array}$ & $N=15(\mathrm{c})$ & $N=15(\mathrm{PBO})$ & $24.2 \pm 2.8$ \\
\hline
\end{tabular}

Age (baseline and in years), CSD - clinical study design, DUR - duration (days), RES - resveratrol (mg/dl), $N$ - number of subjects, $P$ - parallel, C-O - cross-over, T-P - target-population, BMI - body-mass index $\left(\mathrm{kg} / \mathrm{m}^{2}\right)$, ${ }^{\mathrm{I}}$ different formulation; ${ }^{2} 1 \mathrm{~g} /$ day for 1 week, then $2 \mathrm{~g} /$ day for 1 week, $O H A$ - oral hypoglycaemic agents, $P B O$ - placebo, $c$-capsules, $p$ - pills, $t$-tablets. Faghihzadeh et al. presented data of all 50 subjects, but one patient (control group) discontinued the study because of disliking to continue and one patient (intervention group) may have been omitted from the final evaluation having body weight loss more than $10 \%$ of baseline.

of subjects in each study ranged from 16 to 90 , and the concentration of RES ranged from 10 to $2000 \mathrm{mg} / \mathrm{dl}$. The duration of RES treatment varied from 14 to 365 days. We noted some heterogeneity in the subjects recruited involving healthy subjects, obese subjects, subjects with a 'stable' CAD, individuals with T2DM, patients with non-alcoholic fatty liver disease (NAFLD), and patients with Met-S.

\section{Statistical evaluation}

The results of a mixed-effects analysis to investigate the influence of RES on the cardiometabolic risk factors are shown in Table III. Comparison of treatment with control groups revealed a positive influence of RES on the risk factors HOMA-IR (Homeostatic Model Assessment-Insulin Resistance), which resulted in a mean difference of -0.520 (95\% Cl: $-1.127,-0.014 ; p<0.001)$. The mean difference for LDL-C (mg/dl) was -0.569 (95\% Cl: $-1.163,0.026 ; p=0.061$ ), while that for $\mathrm{T}$-Chol was -0.492 (95\% Cl: $-1.073,-0.242 ; p=0.097)$. The remaining cardio-metabolic risk factors did not show any significant influence of RES. Figure 2 shows the forest plots of the influence of RES on some of the studied risk factors for heart disease. The influence of RES on HOMA-IR was 
Usefulness of resveratrol supplementation in decreasing cardiometabolic risk factors comparing subjects with metabolic syndrome and healthy subjects with or without obesity: meta-analysis using multinational, randomised, controlled trials

Table III. Meta-analysis of resveratrol supplementation on cardiometabolic risk factors

\begin{tabular}{|c|c|c|c|c|c|c|c|c|c|c|}
\hline Variable & $N$ & $\begin{array}{c}\text { Point } \\
\text { estimate }\end{array}$ & $\begin{array}{c}\text { Standard } \\
\text { error }\end{array}$ & $\begin{array}{l}\text { Lower } \\
\text { limit }\end{array}$ & $\begin{array}{l}\text { Upper } \\
\text { limit }\end{array}$ & $P$-value & $Q$-value & $\mathrm{d} f(\mathrm{Q})$ & $\begin{array}{c}P \text {-value } \\
\text { (Q) }\end{array}$ & $I^{2}$ \\
\hline \multicolumn{11}{|l|}{ Overall: } \\
\hline $\mathrm{CRP}[\mathrm{mg} / \mathrm{l}]$ & 5 & -0.208 & 0.490 & -1.169 & 0.753 & 0.671 & 44.289 & 4 & 0.000 & 90.968 \\
\hline $\mathrm{DBP}[\mathrm{mm} \mathrm{Hg}]$ & 7 & -0.006 & 0.235 & -0.466 & 0.454 & 0.980 & 20.879 & 6 & 0.002 & 71.263 \\
\hline Glucose [mg/dl] & 13 & -0.330 & 0.328 & -0.973 & 0.313 & 0.315 & 126.431 & 12 & 0.000 & 90.509 \\
\hline $\mathrm{HDL}-\mathrm{C}[\mathrm{mg} / \mathrm{dl}]$ & 14 & 0.238 & 0.310 & -0.370 & 0.846 & 0.443 & 145.031 & 13 & 0.000 & 91.036 \\
\hline HOMA-IR & 8 & -0.570 & 0.284 & -1.127 & -0.014 & 0.045 & 31.148 & 7 & 0.000 & 77.527 \\
\hline Insulin $[\mu \mid \mathrm{U} / \mathrm{ml}]$ & 10 & -0.134 & 0.226 & -0.576 & 0.309 & 0.554 & 33.846 & 9 & 0.000 & 73.409 \\
\hline $\mathrm{LDL}-\mathrm{C}[\mathrm{mg} / \mathrm{dl}]$ & 12 & -0.653 & 0.354 & -1.347 & 0.041 & 0.065 & 135.390 & 11 & 0.000 & 91.875 \\
\hline $\mathrm{SBP}[\mathrm{mm} \mathrm{Hg}]$ & 8 & -0.414 & 0.265 & -0.932 & 0.105 & 0.118 & 31.818 & 7 & 0.000 & 78.000 \\
\hline T-chol [mg/dl] & 14 & -0.624 & 0.341 & -1.291 & 0.044 & 0.067 & 171.272 & 13 & 0.000 & 92.410 \\
\hline TG [mg/dl] & 12 & -0.078 & 0.370 & -0.804 & 0.648 & 0.834 & 136.418 & 11 & 0.000 & 91.937 \\
\hline \multicolumn{11}{|c|}{ Metabolic syndrome: } \\
\hline $\mathrm{CRP}[\mathrm{mg} / \mathrm{l}]$ & 4 & -0.192 & 0.641 & -1.448 & 1.063 & 0.764 & 44.289 & 3 & 0.000 & 93.226 \\
\hline $\mathrm{DBP}[\mathrm{mm} \mathrm{Hg}]$ & 3 & 0.119 & 0.417 & -0.698 & 0.936 & 0.775 & 10.274 & 2 & 0.006 & 80.533 \\
\hline Glucose [mg/dl] & 4 & -1.559 & 0.733 & -2.996 & -0.122 & 0.033 & 43.228 & 3 & 0.000 & 93.060 \\
\hline $\mathrm{HDL}-\mathrm{C}[\mathrm{mg} / \mathrm{dl}]$ & 7 & 1.235 & 0.585 & 0.088 & 2.382 & 0.035 & 114.981 & 6 & 0.000 & 94.782 \\
\hline HOMA-IR & 2 & -1.113 & 0.233 & -1.570 & -0.656 & 0.000 & 0.007 & 1 & 0.935 & 0.000 \\
\hline Insulin $[\mu \mathrm{IU} / \mathrm{ml}]$ & 2 & -0.576 & 0.582 & -1.716 & 0.565 & 0.323 & 5.642 & 1 & 0.018 & 82.277 \\
\hline $\mathrm{LDL}-\mathrm{C}[\mathrm{mg} / \mathrm{dl}]$ & 7 & -1.175 & 0.583 & -2.319 & -0.031 & 0.044 & 118.830 & 6 & 0.000 & 94.951 \\
\hline $\mathrm{SBP}[\mathrm{mm} \mathrm{Hg}]$ & 4 & 0.047 & 0.237 & -0.417 & 0.510 & 0.844 & 5.704 & 3 & 0.127 & 47.404 \\
\hline T-chol [mg/dl] & 7 & -1.898 & 0.725 & -3.318 & -0.477 & 0.009 & 159.099 & 6 & 0.000 & 96.229 \\
\hline $\mathrm{TG}[\mathrm{mg} / \mathrm{dl}]$ & 6 & -0.744 & 0.771 & -2.256 & 0.768 & 0.335 & 133.582 & 5 & 0.000 & 96.257 \\
\hline \multicolumn{11}{|l|}{ Obese healthy: } \\
\hline $\mathrm{CRP}[\mathrm{mg} / \mathrm{ll}]$ & 1 & -0.263 & 0.318 & -0.885 & 0.360 & 0.408 & 0.000 & 0 & 1.000 & 0.000 \\
\hline $\mathrm{DBP}[\mathrm{mm} \mathrm{Hg}]$ & 4 & -0.100 & 0.320 & -0.727 & 0.526 & 0.753 & 10.029 & 3 & 0.018 & 70.086 \\
\hline Glucose [mg/dl] & 9 & 0.145 & 0.314 & -0.470 & 0.761 & 0.643 & 52.751 & 8 & 0.000 & 84.835 \\
\hline $\mathrm{HDL}-\mathrm{C}[\mathrm{mg} / \mathrm{dl}]$ & 7 & -0.289 & 0.284 & -0.845 & 0.268 & 0.309 & 26.859 & 6 & 0.000 & 77.661 \\
\hline HOMA-IR & 6 & -0.381 & 0.337 & -1.042 & 0.280 & 0.259 & 21.849 & 5 & 0.001 & 77.115 \\
\hline Insulin $[\mu \mathrm{IU} / \mathrm{ml}]$ & 8 & -0.017 & 0.240 & -0.488 & 0.454 & 0.944 & 22.113 & 7 & 0.002 & 68.344 \\
\hline LDL-C [mg/dl] & 5 & 0.027 & 0.235 & -0.433 & 0.487 & 0.907 & 8.427 & 4 & 0.077 & 52.536 \\
\hline $\mathrm{SBP}[\mathrm{mm} \mathrm{Hg}]$ & 4 & -0.873 & 0.370 & -1.598 & -0.149 & 0.018 & 12.212 & 3 & 0.007 & 75.434 \\
\hline T-chol [mg/dl] & 7 & -0.018 & 0.165 & -0.342 & 0.306 & 0.912 & 9.729 & 6 & 0.137 & 38.331 \\
\hline $\mathrm{TG}[\mathrm{mg} / \mathrm{dl}]$ & 6 & 0.104 & 0.150 & -0.189 & 0.398 & 0.486 & 2.800 & 5 & 0.731 & 0.000 \\
\hline
\end{tabular}

SE - standard error, $N$ - number of studies.

overall significant. HOMA-IR involved eight stud- where this data was available, were positioned on ies, which yielded a mean difference of -0.520 , as the left side of the zero-centre line. Five studies mentioned above. More precisely, looking at Fig- showed no difference, and the overall summary ure $2 \mathrm{~A}$, i.e. that of HOMA-IR, most of the SDs in (mean) difference for all the nine studies included the means for each of the nine studies examined, in HOMA-IR analysis was negative and significant. 
Table III. Cont.

\begin{tabular}{|c|c|c|c|c|c|c|c|c|c|c|}
\hline Variable & $N$ & $\begin{array}{c}\text { Point } \\
\text { estimate }\end{array}$ & $\begin{array}{l}\text { Standard } \\
\text { error }\end{array}$ & $\begin{array}{l}\text { Lower } \\
\text { limit }\end{array}$ & $\begin{array}{l}\text { Upper } \\
\text { limit }\end{array}$ & $P$-value & $Q$-value & $\mathrm{d} f(\mathrm{Q})$ & $\begin{array}{c}P \text {-value } \\
\text { (Q) }\end{array}$ & $I^{2}$ \\
\hline \multicolumn{11}{|c|}{ Both male and female: } \\
\hline $\mathrm{CRP}[\mathrm{mg} / \mathrm{l}]$ & 4 & -0.192 & 0.641 & -1.448 & 1.063 & 0.764 & 44.289 & 3 & 0.000 & 93.226 \\
\hline $\mathrm{DBP}[\mathrm{mm} \mathrm{Hg}]$ & 4 & -0.055 & 0.327 & -0.695 & 0.585 & 0.866 & 13.435 & 3 & 0.004 & 77.671 \\
\hline Glucose [mg/dl] & 8 & -0.748 & 0.400 & -1.533 & 0.036 & 0.062 & 81.112 & 8 & 0.000 & 91.370 \\
\hline $\mathrm{HDL}-\mathrm{C}[\mathrm{mg} / \mathrm{dl}]$ & 10 & 0.608 & 0.375 & -0.128 & 1.344 & 0.105 & 117.445 & 10 & 0.000 & 92.337 \\
\hline HOMA-IR & 3 & -0.668 & 0.265 & -1.187 & -0.149 & 0.012 & 4.055 & 2 & 0.132 & 50.677 \\
\hline Insulin $[\mu \mathrm{IU} / \mathrm{ml}]$ & 5 & -0.634 & 0.186 & -0.998 & -0.270 & 0.001 & 6.137 & 4 & 0.189 & 34.822 \\
\hline LDL-C [mg/dl] & 9 & -0.876 & 0.453 & -1.763 & 0.012 & 0.053 & 123.867 & 9 & 0.000 & 93.541 \\
\hline $\mathrm{SBP}[\mathrm{mm} \mathrm{Hg}]$ & 4 & -0.285 & 0.400 & -1.069 & 0.499 & 0.476 & 19.639 & 3 & 0.000 & 84.724 \\
\hline T-chol [mg/dl] & 10 & -0.930 & 0.461 & -1.832 & -0.027 & 0.044 & 165.727 & 10 & 0.000 & 94.569 \\
\hline TG [mg/dl] & 8 & -0.388 & 0.554 & -1.475 & 0.698 & 0.483 & 134.626 & 8 & 0.000 & 94.800 \\
\hline \multicolumn{11}{|l|}{ Male: } \\
\hline CRP $[\mathrm{mg} / \mathrm{l}]$ & 1 & -0.263 & 0.318 & -0.885 & 0.360 & 0.408 & 0.000 & 0 & 1.000 & 0.000 \\
\hline $\mathrm{DBP}[\mathrm{mm} \mathrm{Hg}]$ & 2 & -0.269 & 0.331 & -0.917 & 0.379 & 0.415 & 1.561 & 1 & 0.212 & 35.923 \\
\hline Glucose $[\mathrm{mg} / \mathrm{dl}]$ & 4 & 0.847 & 0.804 & -0.730 & 2.424 & 0.293 & 33.894 & 3 & 0.000 & 91.149 \\
\hline $\mathrm{HDL}-\mathrm{C}[\mathrm{mg} / \mathrm{dl}]$ & 3 & -0.909 & 0.920 & -2.711 & 0.894 & 0.323 & 23.361 & 2 & 0.000 & 91.439 \\
\hline HOMA-IR & 4 & -0.629 & 0.643 & -1.889 & 0.631 & 0.328 & 23.743 & 3 & 0.000 & 87.365 \\
\hline Insulin $[\mu \mathrm{IU} / \mathrm{ml}]$ & 4 & 0.507 & 0.407 & -0.291 & 1.306 & 0.213 & 10.872 & 3 & 0.012 & 72.407 \\
\hline LDL-C [mg/dl] & 2 & 0.418 & 0.253 & -0.078 & 0.914 & 0.098 & 0.375 & 1 & 0.540 & 0.000 \\
\hline $\mathrm{SBP}[\mathrm{mm} \mathrm{Hg}]$ & 3 & -0.825 & 0.417 & -1.642 & -0.009 & 0.048 & 5.797 & 2 & 0.055 & 65.500 \\
\hline T-chol [mg/dl] & 3 & 0.057 & 0.224 & -0.382 & 0.495 & 0.801 & 0.092 & 2 & 0.955 & 0.000 \\
\hline $\mathrm{TG}[\mathrm{mg} / \mathrm{dl}]$ & 3 & 0.243 & 0.225 & -0.198 & 0.685 & 0.280 & 1.213 & 2 & 0.545 & 0.000 \\
\hline
\end{tabular}

SE - standard error, $N$ - number of studies.

None of the summaries of the differences of the means for the remaining examined risk factors were significant. The LDL-C was involved in 17 studies (Figure $2 \mathrm{~B}$ ). The influence of RES on this risk factor was negative, with a summary mean difference of -0.569 (95\% Cl: $-10.163,0.026 ; p=$ 0.061 ). Similarly, T-Chol was included in 18 studies, which arrived at a summary mean difference of -0.492 (95\% Cl: $-1.073,-0.242 ; p=0.097$ ) (Figure $2 \mathrm{C}$ ).

The last four columns in Table III describe the characteristics of heterogeneity in the studies. The $Q$-value for each risk factor is a sum that reflects total dispersion and depends on the number of reviews included. All the values of $Q$ were highly significant. A significant amount of $Q$ is evidence that the exact summated mean differences vary. In fact, for instance, the $Q$-value for HOMA-IR was 31.148 ( $p<0.001)$. Overall, the risk factors returned moderate to high heterogene- ity. The greatest heterogeneity was found among the 17 reviews of the T-Chol risk factor, yielding a $Q$-value of 171.272 ( $p<0.001)$. The corresponding $\mathrm{l}$-squared, i.e. the share of the observed variance reflecting real changes in the point estimate, was $92.4 \%$. The lowest amount of heterogeneity resulted from the eight studies involved in DBP, with a $Q$-value of $20.879(p=0.002)$.

\section{Comparison of the effect between Met-S with the group $\mathrm{O} / \mathrm{H}$}

In the Met-S group, there was evidence of RES effect on glucose, LDL-C, and T-Chol, as detected by the mean difference of -1.069 (95\% Cl: -2.107 , $-0.032 ; p=0.043),-0.924$ (95\% Cl: $-1.804,-0.043$; $p=0.040)$, and -1.246 (95\% Cl: $-2.314,-0.178$; $p=0.022$ ), respectively. Similarly, HOMAR-IR was significant, but the number of studies does not allow a reliable meta-analysis conclusion. The $\mathrm{O} / \mathrm{H}$ group showed a significant decrease in systolic 
A

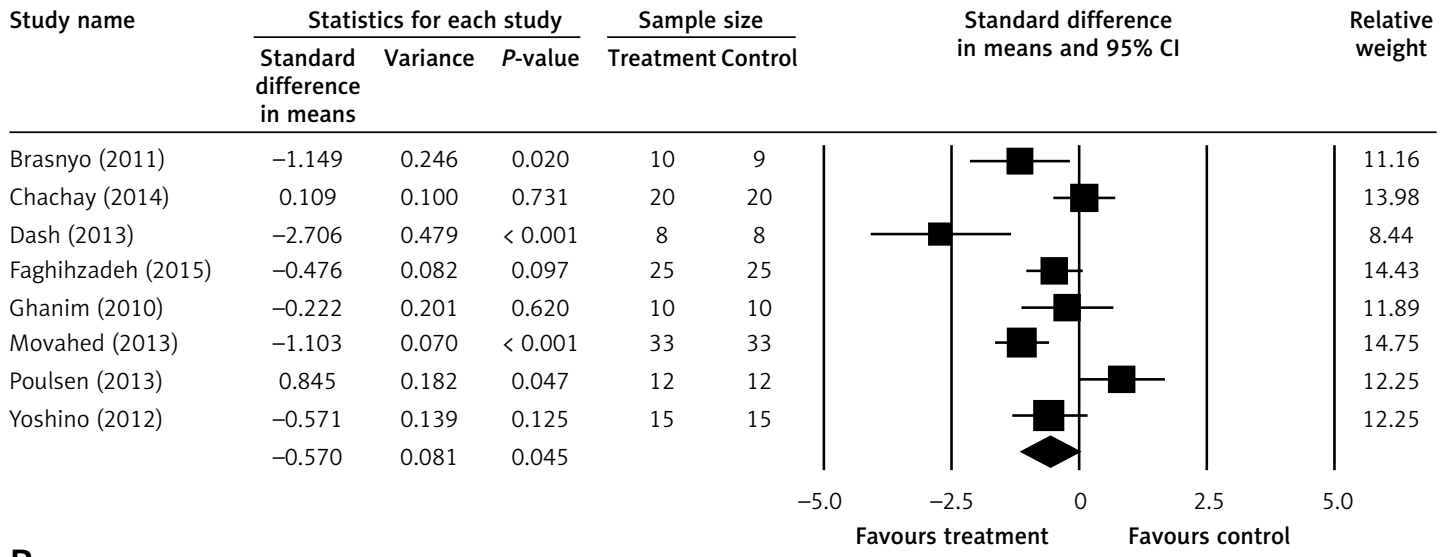

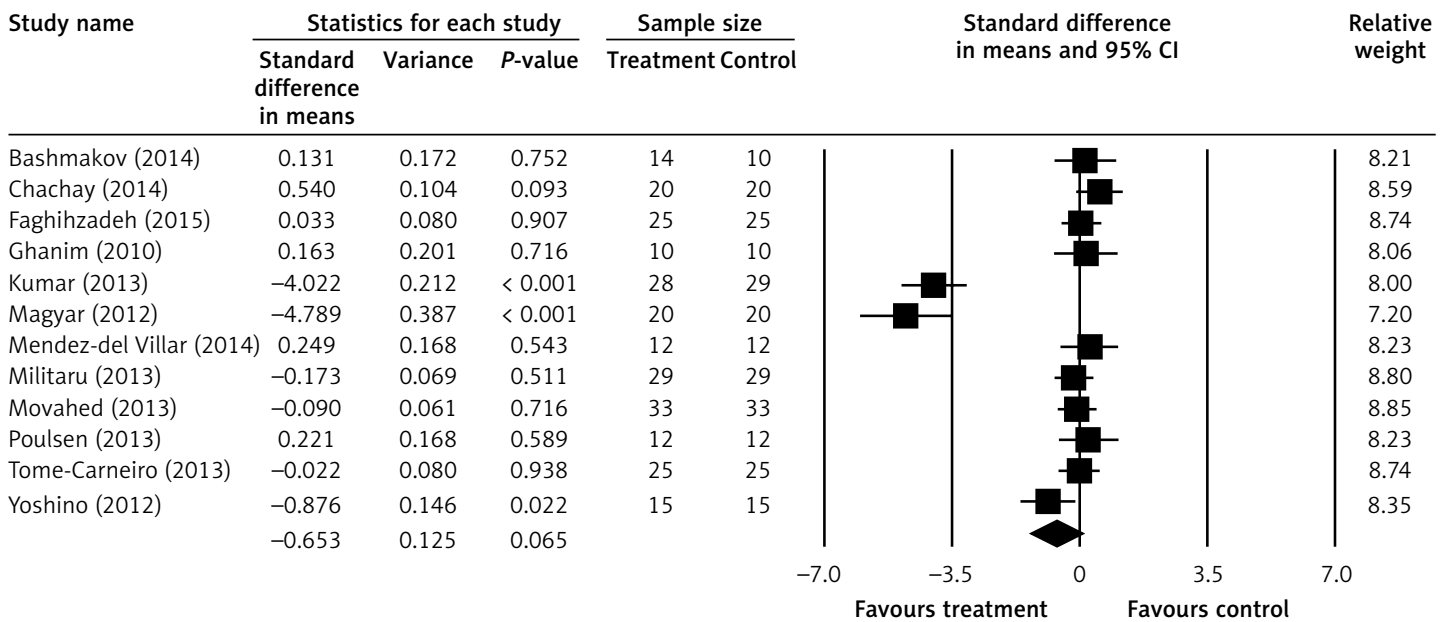

C

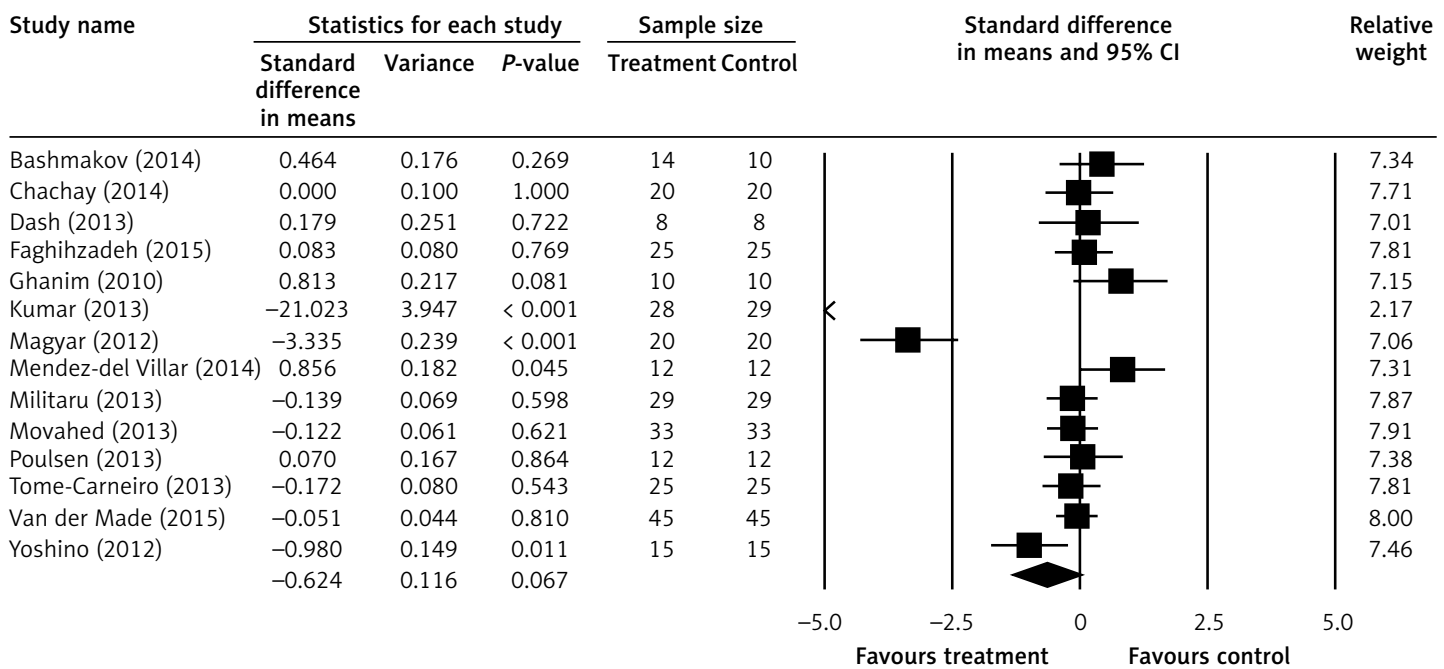

Figure 2. A - Forest plots of the of the influence of resveratrol (RES) on heart disease risk factors targeting the homeostatic model assessment-insulin resistance (HOMA-IR). B - Forest plots of the of the influence of resveratrol (RES) on heart diseases risk factors targeting the low-density lipoprotein-cholesterol (LDL-C) (mg/dl). C - Forest plots of the of the influence of resveratrol (RES) on heart diseases risk factors targeting the total cholesterol (T-chol) (mg/dl). The last row in the study name column refers to the overall evaluation

blood pressure (SBP) in the presence of RES by -0.873 (95\% Cl: $-1.598,-0.149 ; p=0.018)$. In the presence of RES, glucose insignificantly increased among the $\mathrm{O} / \mathrm{H}$ group (mean difference $=0.145$
95\% Cl: $-0.470,-0.761 ; p=0.643)$, while it significantly decreased among the Met-S group. In fact, in the Met-S group, RES reduced the glucose level of -1.069 (95\% Cl: $-2.107,-0.032 ; p=0.043)$. 


\section{Comparison of RES effects across gender groups}

The influence of RES on the risk factors for CVD was examined under female, male, and mixed-sex categories. The female group contained one female-only RCT study, which was insufficient to run a meta-analysis. Regarding the male group, none of the summaries of the mean differences were significant. Conversely, within the mixed-gender group, three risk factors showed significant effects of RES, including HOMA-IR, LDL-C, and insulin. The influence of RES on HOMA-IR involved three studies, which yielded a mean difference of -0.668 (95\% Cl: $-1.187,-0.149 ; p=0.012$ ). The LDL-C $(\mathrm{mg} / \mathrm{dl})$ included 10 studies. The influence of RES on LDL-C was negative, with a summary mean of -0.827 (95\% Cl: $-1.604,-0.049 ; p=0.037$ ). Insulin comprised five studies, with a summary mean of -0.634 (95\% Cl: $-0.998,-0.270 ; p=0.001)$. The insignificant and relatively low values of $Q$ for HOMAR-IR and insulin could be attributed to lack of heterogeneity or low precision due to the small number of studies included.

\section{Publication bias assessment}

One of the major issues in our meta-analysis was to ensure that point estimates were not computed from a biased collection of studies. The benefit is that exaggeration of the true effect size of treatment can be avoided. Hence, we assessed how many biases could be present in our meta-analysis and examined their potential impact on our findings. We used Egger's method of bias assessment, which recommends the use of the inverse of the SE, i.e. precision, to predict the standardised effect size. We found that the intercept $\left(B_{0}\right)$, which is used for capturing the bias, was not significant: $0.541(95 \% \mathrm{Cl}:-3.367$, 4.449; 1 -tailed $p$-value $=0.386)$. We estimated the impact of the bias using Duval and Tweedie's method, which may suggest imputation of missing studies. Following the random effects model

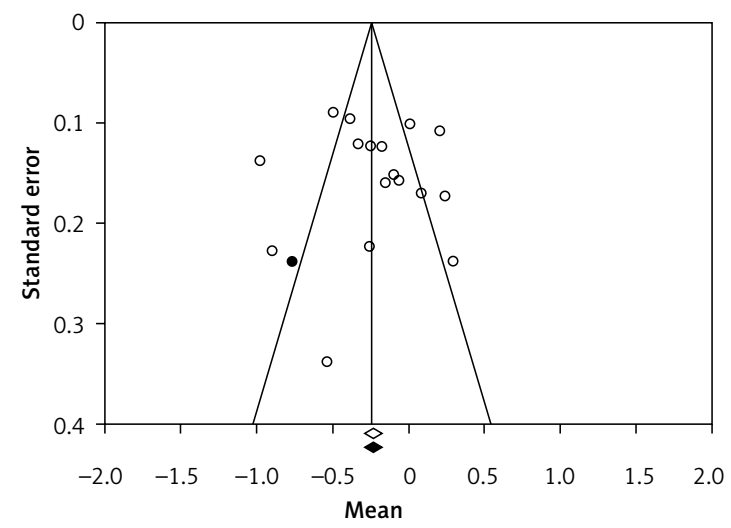

Figure 3. Publication bias plot and without affecting any changes, the summary (mean) difference for the combined studies was -0.196 (95\% Cl: $-0.341,-0.050)$. We applied the trim-and-fill method [87, 88], a simple funnelplot-based method of testing and adjusting for publication bias in meta-analyses (Figure 3). The summary (mean) difference was -0.240 (95\% $\mathrm{Cl}:-0.384,-0.097)$. Hence the absolute value of the difference between imputed and non-imputed was -0.054 , which means that the corrected method arrived at a slightly lower mean difference compared to the original analysis. There may be a bias, but its impact would be minor regarding RES input difference in the context of our study. In other words, the inclusion of only relevant studies might shift the results probably without changing the key findings [79].

\section{Discussion}

Numerous studies have shown that RES may protect against CVD through several potential mechanisms. These studies, reviewed initially by Sahebkar [45] in 2013, include downregulation of proinflammatory cytokines, inhibition of LDL oxidation, improved insulin sensitivity, lowering of arterial blood pressure, inhibition of platelet aggregation, improvement of the endothelial function, as well as circumvention of cardiac hypertrophy/fibrosis. The molecular mechanisms of protective effects of RES may include the activations of SIRT-1 and AMPK, and inhibitions of cyclooxygenases and NF- $\mathrm{B}$ in the downregulation of pro-inflammatory stimuli, as observed in Met-S and liver tumours $[32,35]$. Despite the promising results of targeting complex array of signalling pathways in pre-clinical studies, conflicting results have been observed in some RCTs [89]. Sahebkar $[45,46]$ showed a lack of efficacy of RES antagonising CRP and on selected CVD risk factors, while Hausenblas et al. [49] showed positive effects on SBP and creatinine.

In this systematic search to conduct a meta-analysis, the effects of RES supplementation were evaluated through an analysis of 22 RCTs with 800 subjects. It seems plausible to suggest that RES supplementation positively influences HOMA-IR, LDL-C, and T-Chol. Our investigation may have several strengths. We conducted a comprehensive search, assessed inclusion and exclusion criteria, and with the scrutiny of careful perused available datasets, divided the studies into two groups. Exclusion criteria included studies that were duplicated, showed overlapping, and, according to the authors, were considered non-relevant. All studies were evaluated singly and scored by three authors (BoC, JF, BrC), and any inclusion or exclusion needed to have full consensus. It is conceivable that some studies used in other me- 
ta-analyses were not included in this investigation. Despite these discordances, the choice to include a specific study was derived from the careful examination of the articles. It is also predictable that articles subsequent to our systematic search may add value to the meta-analysis. We would also be interested in including studies published after this research was concluded, but this would require more investigation and perusal of articles. It is not feasible because the three independent authors are currently located in different places, and changing the consensus would introduce some bias to the study. On the other hand, we would consider appropriate discussion of some of the most recent studies that are extremely relevant to our investigation.

It is useful to mention some of the most relevant studies. A meta-regression analysis based on 17 studies, which is a tool used in meta-analysis to examine the impact of moderator variables on study effect size using regression-based techniques, revealed a positive association between systolic BP-lowering RES activity BMI at baseline [90]. In this Italian study, Fogacci et al. found that RES was moderately well-tolerated without serious adverse events in most of the eligible trials [90]. These authors suggest that RES may promote cardiovascular health, mostly when used in high daily dose ( $\geq 300 \mathrm{mg} /$ day) and in diabetic patients. Akbari et al. evaluated 28 RCTs and showed that RES intervention significantly increased the levels of flow-mediated dilatation among patients with MetS and related disorders, but RES supplements did not affect systolic blood pressure and diastolic blood pressure [91]. Using a variation on the inverse-variance method to incorporate an assumption that the different studies are evaluating different, but related, intervention effects, Asgary et al. found a significant impact of RES supplementation on glucose level and waist circumference compared with the control group. Also, these authors combined the results of studies on rat samples showing a net effect of RES on decreasing weight and systolic blood pressure. According to these authors, it can influence significantly the increasing HDL level but was not significantly effective on total cholesterol. The significative effect was seen at the dosage of greater than $500 \mathrm{mg}$ and with long-term interventions equal to or more than 10 weeks [92]. Zhao et al. evaluated 10 randomised controlled trials, including eight randomised, parallel, controlled studies and two crossover-controlled studies [93]. The results on 363 patients with type 2 diabetes mellitus showed that longer RES supplementation ( $\geq 6$ months) can reduce triglyceride levels, but there was an increase of total cholesterol in patients within obesity range undergoing RES supplementation. Mousavi et al. performed a meta-analysis including 28 trials, with data suggesting that there is an effect of RES on weighted mean differences, BMI, and waist circumference [94]. No significant effect of RES supplementation on fat mass was found. A significant reduction was detected for dosage of $<500 \mathrm{mg} /$ day, long-term interventions ( $\geq 3$ month), and on people with obesity. It may be part of a personalised therapy $[95,96]$. Substantially, there are many nutraceuticals described in medical literature and Chinese traditional medicine with different levels of effectiveness and evidence on lowering the cardiometabolic risk in patients with metabolic syndrome [97], but RES is probably one of the most studied compounds. Nevertheless, RES seems to improve the lipid metabolic levels or other cardiometabolic risks only in some patients affected with metabolic syndrome, suggesting that personalised medicine and a personalised approach should be a line of action in these patients.

Our document is not a systematic review discussing the outcomes of the single studies, but we considered some biochemical values that have been evaluated and clinical definitions that are being updated. Our evaluation may help in supporting the use of RES in health policies in the second half of the $21^{\text {st }}$ century. A meta-analysis is not a final study but has a temporary value according to the definitions used in the period of data collection. In the future, more uniformity would be advisable to perform a meta-analysis. However, our meta-analysis may show some beneficial influence of RES supplementation on cardiometabolic risk factors in subjects with Met-S with CVD, while RES supplementation to $\mathrm{O} / \mathrm{H}$ individuals without cardiometabolic risk factors failed to demonstrate any significant change. Our results seem to be in contrast with some previous evidence [45], although a separation of the 10 RCTs of mixed cardiometabolic risks did not occur in previous studies. In line with our results, some positive effects of RES supplementation for SBP, and creatinine in T2DM, were found in another study [49]. Our investigation included more reviews than those involved in Hausenblas et al. [49]. Our study seems to provide some evidence for the benefits of RES supplementation in patients with cardiometabolic risk factors.

On the other hand, our investigation has some limitations, including the variable size of the groups in the single studies, ranging from 16 to 90 subjects, some heterogeneity of the target population, the variable study duration (14 through 365 days), and the exclusion of non-English language texts. Also, some of the most recent literature data were not included, but expanding the meta-analysis may not have made a difference, because we have seen in this literature different inclusion criteria with groups ranging quite vari- 
ably. Moreover, RES supplementation was used in different formulations, including modified RES supplementation [86], grape extract RES [80, 84, 98], and purified extract of Polygonum cuspidatum containing RES [72], among others, with a dosage ranging from 10 to $2000 \mathrm{mg} /$ day, therefore leaving the optimal choice of dose, duration, and even the RES preparation open to debate. While there are many individuals living healthy lives in North America despite an obese status, the metabolic/physiological responses to RES may be different between obese and non-obese individuals. Although it may be difficult to consider an overweight subject as healthy, there is some evidence that fat and non-obese are metabolically entirely equivalent. Currently, the category healthy/obese in some countries is an actual part of the general population. Overweight and obesity have reached epidemic proportions in some countries, not only in the USA, but increasing in Europe, Asia, and Africa. The very high prevalence of class III obesity $\left(\mathrm{BMI} \geq 40 \mathrm{~kg} / \mathrm{m}^{2}\right)$ is concerning, having reached $3 \%$ in the USA. Recently some controversy has encircled the idea that some obese subjects can be considered healthy regarding their metabolic and cardiorespiratory fitness, which has been termed the 'obesity paradox'. There is apparently a very favourable prognosis in patients with obesity, who have no identifiable metabolic abnormalities and who have preserved some of their fitness [99]. In our study, we did not consider $\mathrm{HbA}_{1 c}$ because of the heterogeneity of the time frame identified in several studies. Because $\mathrm{HbA}_{1 c}$ is a measure of average plasma glucose concentration over a 3-month period, we could not examine studies of at least 3-months duration accurately (at a minimum) to be evaluated in our meta-analysis. In the future, we would like to review studies with a uniform dosage of RES and a uniform duration of treatment. Both conditions may allow more uniformity in the evaluation of the role of RES in decreasing the risk of significant cardiovascular complications.

In conclusion, despite the limitations that we have mentioned above, we consider that RES supplementation may improve cardiometabolic health, decreasing some risk factors (HOMA-IR, LDL-C, and T-Chol) associated with CVD in some patients, and it should be part of personalised medicine.

\section{Acknowledgments}

Dr. C. Sergi has received research funding from the Women and Children's Health Research Institute, Saudi Cultural Bureau, and the Canadian Foundation for Women's Health (CFWH) (Award 2009: CFWH, General Research Grant Dr. L. Hornberger and Dr. C. Sergi). Dr. C. Sergi has received fees for serving as a grant reviewer for the Health and Medical Research Fund (HMRF), Hong Kong Special Administrative Region, Polish National Health Centre, and as a consultant for Guidepoint. Some of these grant reviews contemplated cardio-metabolic risk factors.

\section{Conflict of interest}

The authors declare no conflict of interest.

\section{References}

1. Abdualmjid RJ, Sergi C. Hepatotoxic botanicals - an evidence-based systematic review. J Pharm Pharm Sci 2013; 16: 376-404.

2. Burroughs Pena MS, Rollins A. Environmental exposures and cardiovascular disease: a challenge for health and development in low- and middle-income countries. Cardiol Clin 2017; 35: 71-86.

3. Pfeffer MA. Heart failure and hypertension: importance of prevention. Med Clin North Am 2017; 101: 19-28.

4. Chiu B, Sergi C. Dilated cardiomyopathy: etio-morphologic investigation. Front Biosci 2010; 2: 112-6.

5. Mohammed S, Bahitham W, Chan A, et al. Mitochondrial DNA related cardiomyopathies. Front Biosci 2012; 4: 1706-16.

6. Mackey RH, Kuller LH, Moreland LW. Cardiovascular disease risk in patients with rheumatic diseases. Clin Geriatr Med 2017; 33: 105-17.

7. Regitz-Zagrosek V, Kararigas G. Mechanistic pathways of sex differences in cardiovascular disease. Physiol Rev 2017; 97: 1-37.

8. Diaz-Gerevini GT, Repossi G, Dain A, et al. Beneficial action of resveratrol: how and why? Nutrition 2016; 32: 174-8.

9. Amiot MJ, Riva C, Vinet A. Effects of dietary polyphenols on metabolic syndrome features in humans: a systematic review. Obes Rev 2016; 17: 573-86.

10. Christenson J, Whitby SJ, Mellor D, et al. The effects of resveratrol supplementation in overweight and obese humans: a systematic review of randomized trials. Metab Syndr Relat Disord 2016; 14: 323-33.

11. Fry JL, Al Sayah L, Weisbrod RM, et al. Vascular smooth muscle sirtuin-1 protects against diet-induced aortic stiffness. Hypertension 2016; 68: 775-84.

12. Li YC, Liu YM, Shen JD, et al. Resveratrol ameliorates the depressive-like behaviors and metabolic abnormalities induced by chronic corticosterone injection. Molecules 2016; 21: pii: E1341.

13. Reddy BR, Maitra S, Jhelum P, et al. Sirtuin 1 and 7 mediate resveratrol-induced recovery from hyper-anxiety in high-fructose-fed prediabetic rats. J Biosci 2016; 41: 407-17.

14. Rogacka D, Piwkowska A, Audzeyenka I, et al. SIRT1AMPK crosstalk is involved in high glucose-dependent impairment of insulin responsiveness in primary rat podocytes. Exp Cell Res 2016; 349: 328-38.

15. Lam DW, LeRoith D. Metabolic syndrome. In: Endotext. De Groot LJ, Chrousos G, Dungan K, et al. (eds.). South Dartmouth (MA) 2000.

16. Shin JA, Lee JH, Lim SY, et al. Metabolic syndrome as a predictor of type 2 diabetes, and its clinical interpretations and usefulness. J Diabetes Investig 2013; 4: 334-43.

17. Agirbasli M, Tanrikulu AM, Berenson GS. Metabolic syndrome: bridging the gap from childhood to adulthood. Cardiovasc Ther 2016; 34: 30-6. 
18. El-Hattab AW, Scaglia F. Mitochondrial cardiomyopa thies. Front Cardiovasc Med 2016; 3: 25.

19. Hsu YH, Yogasundaram H, Parajuli N, et al. MELAS syndrome and cardiomyopathy: linking mitochondrial function to heart failure pathogenesis. Heart Fail Rev 2016; 21: 103-16.

20. Landecho MF, Moncada R, Valenti V, et al. Cardiovascular prevention in obese patients. Curr Pharm Des 2016; 22: 5687-97.

21. Ruiz-Ramirez A, Lopez-Acosta O, Barrios-Maya MA, et al. Cell death and heart failure in obesity: role of uncoupling proteins. Oxid Med Cell Longev 2016; 2016: 9340654.

22. Ding C, Chan Z, Magkos F. Lean, but not healthy: the 'metabolically obese, normal-weight' phenotype. Curr Opin Clin Nutr Metab Care 2016; 19: 408-17.

23. Arroyo-Johnson C, Mincey KD. Obesity epidemiology worldwide. Gastroenterol Clin North Am 2016; 45: 571-9.

24. Renaud S, de Lorgeril M. Wine, alcohol, platelets, and the French paradox for coronary heart disease. Lancet 1992; 339: 1523-6.

25. Siemann EH, Creasy LI. Concentration of the phytoalexiin resveratrol in wine. Am J Enol Vitic 1992; 43: 49-52.

26. Park EJ, Pezzuto JM. The pharmacology of resveratrol in animals and humans. Biochim Biophys Acta 2015; 1852: 1071-113.

27. Safari F, Zarei F, Shekarforoush S, et al. Combined 1,25-dihydroxy-vitamin $d$ and resveratrol: a novel therapeutic approach to ameliorate ischemia reperfusion-induced myocardial injury. Int J Vitam Nutr Res 2015; 85: 174-84.

28. Cavdar Z, Egrilmez MY, Altun ZS, et al. Resveratrol reduces matrix metalloproteinase-2 activity induced by oxygen-glucose deprivation and reoxygenation in human cerebral microvascular endothelial cells. Int J Vitam Nutr Res 2012; 82: 267-74

29. Bonnefont-Rousselot D. Resveratrol and cardiovascular diseases. Nutrients 2016; 8: pii: E250.

30. Fan E, Jiang S, Zhang L, et al. Molecular mechanism of apoptosis induction by resveratrol, a natural cancer chemopreventive agent. Int J Vitam Nutr Res 2008; 78: 3-8.

31. Chen Y, Liu H, Zhang H, et al. The sirt1/NF-kappaB signaling pathway is involved in regulation of endothelin type $B$ receptors mediated by homocysteine in vascula smooth muscle cells. Biomed Pharmacother 2016; 84: 1979-85.

32. Kulkarni SS, Canto C. The molecular targets of resveratrol. Biochim Biophys Acta 2015; 1852: 1114-23.

33. Tang X, Ma H, Han L, et al. SIRT1 deacetylates the cardiac transcription factor $\mathrm{Nk} \times 2.5$ and inhibits its transcriptional activity. Sci Rep 2016; 6: 36576.

34. Li H, Xia N, Forstermann U. Cardiovascular effects and molecular targets of resveratrol. Nitric Oxide 2012; 26: 102-10

35. Al-Bahrani R, Tuertcher D, Zailaie S, et al. Differential SIRT1 expression in hepatocellular carcinomas and cholangiocarcinoma of the liver. Ann Clin Lab Sci 2015; 45: 3-9.

36. Kennedy BE, Sharif T, Martell E, et al. NAD+ salvage pathway in cancer metabolism and therapy. Pharmacol Res 2016; 114: 274-83.

37. Sergi C, Shen F, Liu SM. Insulin/IGF-1R, SIRT1, and FOXOs pathways - an intriguing interaction platform for bone and osteosarcoma. Front Endocrinol 2019; 10: 93.

38. Dyck J. Resveratrol: challenges in translating pre-clinical findings to improved patient outcomes. Biochem Biophy Acta 2015; 1852: 1069-70.

39. Russo MA, Sansone L, Polletta L, et al. Sirtuins and resveratrol-derived compounds: a model for understanding the beneficial effects of the Mediterranean diet. Endocr Metab Immune Disord Drug Targets 2014; 14: 300-8.

40. Diaz M, Degens $H$, Vanhees $L$, et al. The effects of resveratrol on aging vessels. Exp Gerontol 2016; 85: 41-7.

41. Finnell JE, Lombard CM, Melson MN, et al. The protective effects of resveratrol on social stress-induced cytokine release and depressive-like behavior. Brain Behav Immun 2017; 59: 147-57.

42. Ahmad A, Farhan Asad S, Singh S, et al. DNA breakage by resveratrol and $\mathrm{Cu}(\mathrm{II})$ : reaction mechanism and bacteriophage inactivation. Cancer Lett 2000; 154: 29-37.

43. Muqbil I, Beck FW, Bao B, et al. Old wine in a new bottle: the Warburg effect and anticancer mechanisms of resveratrol. Curr Pharm Des 2012; 18: 1645-54.

44. Ullah MF, Bhat SH, Husain E, et al. Pharmacological intervention through dietary nutraceuticals in gastrointestinal neoplasia. Crit Rev Food Sci Nutr 2016; 56: 1501-18.

45. Sahebkar A. Effects of resveratrol supplementation on plasma lipids: a systematic review and meta-analysis of randomized controlled trials. Nutr Rev 2013; 71: 822-35.

46. Sahebkar A, Serban C, Ursoniu S, et al. Lack of efficacy of resveratrol on C-reactive protein and selected cardiovascular risk factors: results from a systematic review and meta-analysis of randomized controlled trials. Int J Cardiol 2015; 189: 47-55.

47. Bashmakov YK, Assaad-Khalil SH, Abou Seif M, et al. Resveratrol promotes foot ulcer size reduction in type 2 diabetes patients. ISRN Endocrinol 2014; 2014: 816307.

48. Goh KP, Lee HY, Lau DP, et al. Effects of resveratrol in patients with type 2 diabetes mellitus on skeletal muscle SIRT1 expression and energy expenditure. Int J Sport Nutr Exerc Metab 2014; 24: 2-13.

49. Hausenblas HA, Schoulda JA, Smoliga JM. Resveratrol treatment as an adjunct to pharmacological management in type 2 diabetes mellitus: systematic review and meta-analysis. Mol Nutr Food Res 2015; 59: 147-59.

50. Hutton B, Moher D, Cameron C. The PRISMA Extension Statement. Ann Intern Med 2015; 163: 566-7.

51. Hutton B, Salanti G, Chaimani A, et al. The quality of reporting methods and results in network meta-analyses: an overview of reviews and suggestions for improvement. PLoS One 2014; 9: e92508.

52. Liberati A, Altman DG, Tetzlaff J, et al. The PRISMA statement for reporting systematic reviews and meta-analyses of studies that evaluate healthcare interventions: explanation and elaboration. BMJ 2009; 339: b2700.

53. Moher D, Altman DG, Liberati A, et al. PRISMA statement. Epidemiology 2011; 22: 128.

54. Moher D, Liberati A, Tetzlaff J, et al. Preferred reporting items for systematic reviews and meta-analyses: the PRISMA statement. Ann Intern Med 2009; 151: 264-9.

55. Shamseer L, Moher D, Clarke M, et al. Preferred reporting items for systematic review and meta-analysis protocols (PRISMA-P) 2015: elaboration and explanation. BMJ 2015; 349: g7647.

56. Al-Bahrani R, Tuertcher D, Zailaie S, et al. Differential SIRT1 expression in hepatocellular carcinomas and cholangiocarcinoma of the liver. Ann Clin Labor Sci 2015; 45: 3-9.

57. Takawira C, D’Agostini S, Shenouda S, et al. Laboratory procedures update on Hirschsprung disease. J Pediatr Gastroenterol Nutr 2015; 60: 598-605.

58. Xu X, Sergi C. Pediatric adrenal cortical carcinomas: histopathological criteria and clinical trials. A systematic review. Contemp Clin Trials 2016; 50: 37-44.

59. Zhang M, Shen F, Petryk A, et al. "English disease": historical notes on rickets, the bone-lung link and child neglect issues. Nutrients 2016; 8: 722. 
60. Li N, Yue H, Jia M, et al. Effect of low-ratio n-6/n-3 PUFA on blood glucose: a meta-analysis. Food Funct 2019; 10: 4557-65.

61. Ding WX, Ni HM, Li M, et al. Nix is critical to two distinct phases of mitophagy, reactive oxygen species-mediated autophagy induction and Parkin-ubiquitin-p62-mediated mitochondrial priming. J Biol Chem 2010; 285: 27879-90.

62. Borenstein M, Hedges LV, Higgins JPT, et al. Introduction to Meta-Analysis. John Wiley \& Sons, Ltd. Chichester, UK 2009.

63. Du H, Bradbury TN, Lavner JA, et al. A comparison of Bayesian synthesis approaches for studies comparing two means: a tutorial. Res Synth Methods 2020; 11 36-65.

64. Hemila H, Friedrich JO. Many continuous variables should be analyzed using the relative scale: a case study of beta2-agonists for preventing exercise-induced bronchoconstriction. Syst Rev 2019; 8: 282.

65. Rubio-Aparicio M, Sanchez-Meca J, Lopez-Lopez JA, et al. Analysis of categorical moderators in mixed-effects meta-analysis: consequences of using pooled versus separate estimates of the residual between-studies variances. Br J Math Stat Psychol 2017; 70: 439-56.

66. Welz T, Pauly M. A simulation study to compare robust tests for linear mixed-effects meta-regression. Res Synth Methods 2020; 11: 331-42.

67. Agarwal B, Campen MJ, Channell MM, et al. Resveratrol for primary prevention of atherosclerosis: clinical tria evidence for improved gene expression in vascular endothelium. Int J Cardiol 2013; 166: 246-8.

68. Brasnyo P, Molnar GA, Mohas M, et al. Resveratrol im proves insulin sensitivity, reduces oxidative stress and activates the Akt pathway in type 2 diabetic patients. Br J Nutr 2011; 106: 383-9.

69. Chachay VS, Macdonald GA, Martin JH, et al. Resveratrol does not benefit patients with nonalcoholic fatty liver disease. Clin Gastroenterol Hepatol 2014; 12: $2092-$ 103e1-6.

70. Dash S, Xiao C, Morgantini C, et al. High-dose resveratro treatment for 2 weeks inhibits intestinal and hepatic lipoprotein production in overweight/obese men. Arterioscler Thromb Vasc Biol 2013; 33: 2895-901.

71. Faghihzadeh F, Adibi P, Hekmatdoost A. The effects of resveratrol supplementation on cardiovascular risk factors in patients with non-alcoholic fatty liver disease: a randomised, double-blind, placebo-controlled study. Br J Nutr 2015; 114: 796-803.

72. Ghanim H, Sia CL, Abuaysheh S, et al. An antiinflammatory and reactive oxygen species suppressive effects of an extract of Polygonum cuspidatum containing resveratrol. J Clin Endocrinol Metab 2010; 95: E1-8.

73. Kumar A, Negi G, Sharma SS. Neuroprotection by resveratrol in diabetic neuropathy: concepts and mechanisms. Curr Med Chem 2013; 20: 4640-5.

74. Magyar K, Halmosi R, Palfi A, et al. Cardioprotection by resveratrol: a human clinical trial in patients with stable coronary artery disease. Clin Hemorheol Microcirc 2012; 50: 179-87.

75. Méndez-del Villar M, Gonzalez-Ortiz M, Martínez-Abundis E, Pérez-Rubio K, Lizárraga-Valdez R. Effect of resveratrol administration on metabolic syndrome, insulin sensitivity, and insulin secretion. Metab Syndr Relat Disord 2014; 12: 497-501.

76. Militaru C, Donoiu I, Craciun A, et al. Oral resveratrol and calcium fructoborate supplementation in subjects with stable angina pectoris: effects on lipid profiles, in- flammation markers, and quality of life. Nutrition 2013; 29: $178-83$.

77. Movahed A, Nabipour I, Lieben Louis X, et al. Antihyperglycemic effects of short term resveratrol supplementation in type 2 diabetic patients. Evid Based Complement Alternat Med 2013; 2013: 851267.

78. Poulsen MM, Vestergaard PF, Clasen BF, et al. High-dose resveratrol supplementation in obese men: an investigator-initiated, randomized, placebo-controlled clinical trial of substrate metabolism, insulin sensitivity, and body composition. Diabetes 2013; 62: 1186-95.

79. Timmers S, Konings E, Bilet L, et al. Calorie restriction-like effects of 30 days of resveratrol supplementation on energy metabolism and metabolic profile in obese humans. Cell Metab 2011; 14: 612-22.

80. Tome-Carneiro J, Gonzalvez M, Larrosa M, et al. Grape resveratrol increases serum adiponectin and downregulates inflammatory genes in peripheral blood mono nuclear cells: a triple-blind, placebo-controlled, one-year clinical trial in patients with stable coronary artery disease. Cardiovasc Drugs Ther 2013; 27: 37-48.

81. van der Made SM, Plat J, Mensink RP. Resveratrol does not influence metabolic risk markers related to cardio vascular health in overweight and slightly obese subjects: a randomized, placebo-controlled crossover trial. PLoS One 2015; 10: e0118393.

82. Yoshino J, Conte C, Fontana L, et al. Resveratrol supplementation does not improve metabolic function in nonobese women with normal glucose tolerance. Cell Metab 2012; 16: 658-64.

83. Mendez-del Villar M, Gonzalez-Ortiz M, Martinez-Abundis $\mathrm{E}$, et al. Effect of resveratrol administration on metabolic syndrome, insulin sensitivity, and insulin secretion. Metab Syndr Relat Disord 2014; 12: 497-501.

84. Tome-Carneiro J, Larrosa M, Yanez-Gascon MJ, et al. One-year supplementation with a grape extract containing resveratrol modulates inflammatory-related microRNAs and cytokines expression in peripheral blood mononuclear cells of type 2 diabetes and hypertensive patients with coronary artery disease. Pharmacol Res 2013; 72: 69-82.

85. Bhatt JK, Thomas S, Nanjan MJ. Resveratrol supplementation improves glycemic control in type 2 diabetes mellitus. Nutr Res 2012; 32: 537-41.

86. Fujitaka K, Otani H, Jo F, et al. Modified resveratrol Longevinex improves endothelial function in adults with metabolic syndrome receiving standard treatment. Nutr Res 2011; 31: 842-7.

87. Duval S, Tweedie R. Trim and fill: a simple funnel-plot based method of testing and adjusting for publication bias in meta-analysis. Biometrics 2000; 56: 455-63.

88. Weinhandl ED, Duval S. Generalization of trim and fill for application in meta-regression. Res Synth Methods 2012; 3: 51-67.

89. Szkudelski T, Szkudelska K. Resveratrol and diabetes: from animal to human studies. Biochim Biophys Acta 2015; 1852: 1145-54.

90. Fogacci F, Tocci G, Presta V, et al. Effect of resveratrol on blood pressure: a systematic review and meta-analysis of randomized, controlled, clinical trials. Crit Rev Food Sci Nutr 2019; 59: 1605-18.

91. Akbari M, Tamtaji OR, Lankarani KB, et al. The effects of resveratrol supplementation on endothelial function and blood pressures among patients with metabolic syndrome and related disorders: a systematic review and meta-analysis of randomized controlled trials. High Blood Press Cardiovasc Prev 2019; 26: 305-19. 
92. Asgary S, Karimi R, Momtaz S, et al. Effect of resveratrol on metabolic syndrome components: a systematic review and meta-analysis. Rev Endocr Metab Disord 2019; 20: 173-86.

93. Zhao H, Song A, Zhang Y, et al. Effect of resveratrol on blood lipid levels in patients with type 2 diabetes: a systematic review and meta-analysis. Obesity 2019; 27: 94-102.

94. Mousavi SM, Milajerdi A, Sheikhi A, et al. Resveratrol supplementation significantly influences obesity measures: a systematic review and dose-response metaanalysis of randomized controlled trials. Obes Rev 2019; 20: 487-98.

95. Fogacci F, Fogacci S, Cicero A. Resveratrol for high blood pressure: a total failure or the need to identify the right patient? High Blood Press Cardiovasc Prev 2019; 26: 421-3.

96. Fogacci F, Banach M, Cicero AFG. Resveratrol effect on patients with non-alcoholic fatty liver disease: a matter of dose and treatment length. Diabetes Obes Metab 2018; 20: 1798-9.

97. Cicero AFG, Grassi D, Tocci G, et al. Nutrients and nutraceuticals for the management of high normal blood pressure: an evidence-based consensus document. High Blood Press Cardiovasc Prev 2019; 26: 9-25.

98. Tome-Carneiro J, Gonzalvez M, Larrosa M, et al. Consumption of a grape extract supplement containing resveratrol decreases oxidized $L D L$ and $A p o B$ in patients undergoing primary prevention of cardiovascular disease: a triple-blind, 6-month follow-up, placebo-controlled, randomized trial. Mol Nutr Food Res 2012; 56: 810-21.

99. Phillips CM. Metabolically healthy obesity across the life course: epidemiology, determinants, and implications. Ann N Y Acad Sci 2017; 1391: 85-100. 